\title{
Research on Public Policy Performance Evaluation Based on Local Frac- tional Algorithm
}

\author{
Leili Lv ${ }^{*}$
}

College of Humanities Gansu Agriculture University, Lanzhou 730070, China

\begin{abstract}
In this paper, we prompt public policy performance evaluation method based on local fractional algorithm. This paper takes the public value as a basic framework to build a system and it combines the execution process of ecological construction policies with the performance evaluation of the ecological effects. Then it extracts index factors from some aspects such as the "fairness" of the policy process, respect for the subject of "co-production" the management "efficiency" of the government departments, the "sustainability" of ecological effects and so on. The performance evaluation indexes and models of the ecological construction polices based on the public value are of great significance and feasible.
\end{abstract}

Keywords: Algorithm, local fractional algorithm, organization, the public policy performance evaluation.

\section{INTRODUCTION}

Currently, together with the booming of the public management reform in the worldwide and globalization has brought about a lot of changes in the international political and economic policy environment. Against this background, domestic policy makers and experts and scholars of policy science study in many countries have been fully realized that intensifying macro policy analysis and promoting the reform and innovation in the policy making and implementation system are of great significance to the destiny of the country and the regime and the sustainable development of the economy. In recent years, countries all over the world, particularly the developed countries, have conducted wide range of reform and assessment in policy system and policy performance, such as the Reinventing Government Movement in the United States, the Second Nation-Making Movement in the Republic of Korea, and the New Action Examination and Approval Committee in Japan [1]. There have been a lot of achievements in relevant studies. Among them, the issue of how to relax government control and how to strengthen performance assessment has become very popular for policy study and government reform.

The public policy performance evaluation is a new field of study, while study on the demands of evaluation is also in its infancy now. Public policy performance evaluation can be considered as performance-oriented public policy evaluation, or can be considered as measuring the results of the policy in a certain area for a certain time, which is with the Overall Performance Evaluation, public sector performance evaluation and public project performance evaluation, forming the whole system of government performance evaluation.

Study on the demands of evaluation is a key stage of the whole process of evaluation, and decide the concepts, methods and the orientation of the evaluation. Public policy, as an important way of distributing the public resources, has great influence on the society. Essentially saying, the demands of public policy performance evaluation come out of the "bad policy" and its consequences. Like unscientific decisionmaking process; or the policy preference, which is the result of game of different interest groups; or the values the governments holing are different with the public's during the policy process; or the goals of the governments' acting are different with the society's, there are a great many parts of the current public policies are not reasonable. Unreasonable policies brought great waste of resources, attached a negative impact on the public's life, and even caused political crisis, which can be found in histories of many countries in the world. So the public policy performance evaluation is acting an irreplaceable role in the whole process [2].

The motivations, which promote the growing of demands on the public policy performance evaluation, are related to the changes in the financial system, the rise of the government accountability, the rise of civil society, and the developing of the public policy, etc. The reasons that the motivations turned up come from both inside and outside of the government. Different goals of evaluation and various demands from the public, the demands of evaluation are different and changing factors of economy, society and politics are essential to realize the "demands". In the light of that the demands of evaluation are clearing, and the technology are developing, the system of public policy performance evaluation will definitely be built up in someday, and will play an important role in the democratization and legalization progress of our country.

\section{THE BACKGROUND AND FRAME WORK OF PUBLIC PERFORMANCE EVALUATION IN CHINA}

As for management and market orientation-based management tool, performance management played an important role in public administration. Government procurement per- 
formance management is an important part of the government performance management, and also an important content of the construction of the government procurement system, which can provide reliable protection to ensure efficient use of government budget funds and the level of government procurement management. At present stage, issues to be included in the government procurement scope covers almost all areas of social life, not only involving the procurement of goods and services, but also of engineering procurement, involving almost all areas of economic and social life, changes in the size and structure of government procurement will play a huge impact on a country's economic development and industrial structure.

Therefore, the analysis of the value of government procurement performance management and the value evaluation of government procurement become the focuses of government procurement performance management. Public value has long been neglected in government behavior studies, which is contrary to the important role of public value in reality. The public value of public interest in government procurement was especially evident. In the market-oriented society it emphasize on using the market to configure a variety of social resources, highlighting the value of independence and particularity of the value resources, government procurement gets its legitimacy through the performance of system operation, but system performance is often simply replaced by economic achievement, such biases will put the public value and market economy in opposition. The rising level of performance does not necessarily bring an increasing satisfaction and level of trust of citizen on government procurement, at the same time, the government procurement price higher than the market price, the procurement cycle longer than the independent procurement, the utilization of the procurement results and the non-transparency of output efficiency of the financial funds are highly controversial.

Public value as a new public management philosophy, embodied the logic of the government's behavior, to emphasize the public effectiveness of public services and public goods, the government as an administrative body to pursue the public interest as well as the value of the demands in the course of action the government acts to the public advocating public service oriented. Public value shapes the public fife of citizens, promotes public welfare and personal wellbeing. Products and services offered through government procurement contains the value of satisfaction the public needs, the government is to meet the public demand through the implementation of government procurement, with the pursuit of efficiency, fairness, justice, democracy, responsibility and other public values in this process. It's significant to ensure the correct direction of government procurement performance management by entering public value. To rationally combine of the tools of public value based performance management and government procurement performance management, can government procurement performance management solve its own dilemma of powerful instrumental rationality, weak value rationality. Through some problems that appear in government procurement performance management. We can analyze some obstacles in the course of public value practice; the defects can be better understood of the conventional performance management which is val- ued by the instrumental rationality and the sheer pursuit of efficiency.

Government procurement performance management based on public value have significantly different characteristics of traditional performance management, in the main selection, system design, the use of public participation and the results, government procurement collective attention and guidance to the public in the provision of public goods to meet the public demand for government procurement process, identify and create public value. In the government procurement process, through government procurement it is not only to use the limited financial resources to complete the project procurement within the period stipulated, and require attention and respond to the preferences of citizens as the government watch-dog, project owners as the service users, and taxpayer as the funds sources. Public values largely determine whether the government procurement performance really fully reflected, the construction and realization of the public value of government procurement constitutes a path dependence to enhance the level of government procurement performance management, and a direct impact on the direction of government procurement performance management.

At present, China is in an important historical node, the reform has entered a crucial stage and deep water areas, a decisive phase of building a moderately prosperous society. Economic globalization, the globalization of information, domestic and international trade environment and rules challenge enormously on the concepts, systems, procedures and other aspects of government procurement performance management. In this changing environment, market allocation of resources play a decisive role, the government's dominant position has been weakened, and the legitimate profit-driven individuals, to achieve self-worth, but also increased conflict with public values. Government procurement performance management should not only reflect public values, correcting the traditional performance management efficiency dominant values, return to government action's "public" nature and center, but also reflects the economy itself, therefore, the innovation of government procurement performance management, the establishment of public value as the theoretical basis of the government procurement performance management, reflecting the dual needs of theory and practice.

Based on the literature review of the researches and studies on government procurement performance management, combing the theoretical basis of public administration, management, finance, and following the Marxist methodology, in accordance with the logical thinking of theoretical basisreality-analysis-experience-innovative thinking, integrated the use of Marxist dialectical materialism, comparative analysis, logical analysis, value chain analysis, collaborative management theory, seeing recent government procurement performance management as the starting point, starting from the analysis of public value of government procurement, conducting in-depth analysis of the current status and the causes procurement performance management, on the basis of analyzing the of government important role of public values on government procurement performance management, demonstrate that the value of government procurement performance management was born among the public value, the allocation of resources, the distribution of 
goods, the adjustment of interests and so on of government procurement should be subject to public value for the purpose and destination. The ultimate point of the public value based on to government procurement performance management is to create more public value for the public, not just pay attention to the completion of the government procurement tasks and the simple improvements on methods and techniques.

\section{ENVIROMENT POLICY PROMOTING REGIONAL ECONOMY AND PUBLIC EVALUATION}

In china, the average per person of resource and energy is lower than that of world level, but consumption is far above. The "low owns, high consumption" development style makes resources capacity hard to tolerate, and "high emissions" caused by "high consumption" will become the bottleneck of the economic development if the mode of economic development is not changed.

Due to the factors of incomplete consideration and single methods applications, the existing research about the relationship between environmental policy and economic development, failed to fully reveal the mechanism of how the environmental policy promoting economic development, which makes the mechanism behaving as a strong "black cartridge".

Therefore, it is of great significant to study whether environmental policy could promote and how to promote regional economic development and help the construction of ecological economic zone. We have committed that First, transmission path exists, that is, the environmental policy could promote regional economic development through elements accumulation such as motivating technological progress. Second, transmission intensity is measurable, which means under different transmission path the strength of given environment policy to stimulate production elements accumulating, and then promote the economic development is measurable. Third, environment policy performance is comparable, that is, the performance of different environmental policy on equilibrium increasing rate is comparable. Finally, according to the conclusion, environmental policy of the Ecological Economic Zone is simulated: forecast the development of the environment and economy under a given combination of environmental policy; set the ecological and economic zone's economic, environmental strategic objectives, simulate the policy and related conditions required, play the role of policy lab and put forward policy recommendations for the construction of eco-economic Zone.

This study has important academic values, while has important practical value to China's economic development, especially to the Ecological Economic Zone. We construct and solve 7 dynamic Hamilton optimization model one by one, deeply deplore the mechanism by which environment policy promote economic development.

The concrete models are as follows: Neoclassic growth model, named MODEL1 (with environment externality introduced, no government involved) [3]; Neoclassic growth model with government and necessary environmental policy introduced, named MODEL2; New economic growth model with technology advancement introduced, named MODEL3 (corresponding to the transmission path 1) [4]; New economic growth model with human capital accumulation intro- duced, named MODEL4 (corresponding to the transmission path 2); New economic growth model with material capital accumulation introduced named MODEL5 (corresponding to the transmission path 3); New economic growth model with social capital accumulation introduced, named MODEL6 (corresponding to the transmission path 4); The compound model with the above 4 paths synthesized, named MODEL? (corresponding to the compound transmission paths). By constructing and settling the 7 models one by one, we deduce the mechanism by which environmental policy promote the economic development, either one policy under different path, or different policies under the same path, also we compute the degree and elasticity that environment policy works on economic growth and environment protection.

In this paper, we explore endogenous accumulation process of social capital, and thus make the mechanism clear by which social capital promotes economic development. Set the social capital endogenous and relate it with the pollution tax rate, by constructing and settling Hamilton dynamic optimization model, we explore endogenous accumulation process of social capital and mechanism by which social capital promotes economic development. We settle the problem that the existing literature set social capital exogenous and did not consider its accumulation, compared with Owen and Videras, Torgler and Garcia-Valinas: Moreover, the social capital accumulation equation we put forward reflects social capital own essential connotation compared with Roseta-Palma.

We provide empirical proof about how and what degree social capital accumulation promotes economic growth and environmental protection. By using panel data and GMM estimation, we pass the robustness test and the reliability test. Solve the existing research flaw just developed the qualitative analysis on social capital, just taking it as one kind of new forms of capital; Wu Xiaolu 2010 analyzed how social capital promoting economic growth by structural explaining model). Therefore, this empirical research and the mathematical analysis of fourth chapter constitute new attempt of social capital accumulation research, also being the second important innovation.

In the practice of public policies, quantitative assessment can be carried out through establishment of scientific and true quantitative indices on motive, degree, approach, method and performance of citizen participation in formulation of public policies. On the basis of this understanding, in order to enhance the scientific and normative natures and reliability of research on the problem of citizen participation in formulation of public policies, this paper chooses instead to discuss the problem of citizen participation in formulation of public policies of Chinese local governments in terms of quantification, starting with innovation of research methods. The objective is to abstract mathematical models exactly reflecting rules of policies from numerous and complicated phenomena of public policies, and obtain a correct conclusion derived from mathematical methods through further research of mathematical models which hasn't been mentioned in other researches and can be inspected by practice. This is beneficial to drive further development of research on this problem as well as provide some reference for innovation of research methods of political science. Because empirical study is a good research method to solve practical 
problems, the research is based on field investigation, questionnaire and literature search. The field investigation covers 6 provinces, cities and autonomous regions. Case analysis is a special form of empirical study. Accordingly, case analysis is used as applicable in the research of this paper.

\section{THE MODEL OF LOCAL FRACTIONAL ALGO- RITHM}

In the past ten years, Local fractional calculus $[5,6]$ has been widely applied to many fields such as mathematics, image processing and signal processing etc. Some authors have given many definitions of local fractional derivatives and local fractional integrals (also called fractal calculus) [7]. Hereby we rewrite the following local fractional derivative which is given by [8].

The local fractional algorithm can be expressed as following:

$$
\begin{aligned}
& f^{(\alpha)}(x 0)=\left.\frac{d f(x)}{d x^{\alpha}}\right|_{x=x_{0}} \\
& =\lim _{\delta x \rightarrow 0} \frac{\Delta^{\alpha}\left(f(x)-f\left(x_{0}\right)\right)}{\left(x-x_{0}\right)^{\alpha}} \\
& \quad \text { for } 0<a \leq 1 \text { where } \\
& \Delta^{\alpha}\left(f(x)-f\left(x_{0}\right)\right) \cong \\
& \Gamma(1+\alpha) \lim _{x \rightarrow \infty} \Delta\left(f(x)-f\left(x_{0}\right)\right)
\end{aligned}
$$

And local fractional integral of $f(x)$ defined by Eq. 3 .

$$
\begin{aligned}
& { }_{a} I_{b}^{(\alpha)} f(t)=\frac{1}{\Gamma(1+\alpha)} \int_{a}^{b} f(t)(d t)^{\alpha} \\
& =\frac{1}{\Gamma(1+\alpha)} \lim _{\Delta t \rightarrow 0} \sum_{j=0}^{j=N-1} f\left(t_{\mathrm{j}}\right)\left(\Delta t_{\mathrm{j}}\right)^{\alpha}
\end{aligned}
$$

With $\quad \Delta t_{j}=t_{j+1}-t_{j}$ and $\Delta t=\max \left\{\Delta t_{1}, \Delta t_{2}, \cdots, \Delta t_{j}, \cdots\right\}$, where for $j=1,2, \cdots, N-1,\left[t_{j}, t_{j+1}\right]$ is a partition of the interval $[a, b]$ and $t_{0}=a, t_{N}=b$.

If $f(x)$ is defined on the real line $-\infty<x<\infty$, its local fractional Hilbert transform, denoted by $f_{x}^{H, \alpha}(x)$ is defined by

$$
H_{\alpha}\{f(t)\}=\hat{f}_{H}^{\alpha}(x)=\frac{1}{\Gamma(1+\alpha)} \int_{R} \frac{f(t)}{\Gamma t-x)^{\alpha}}(d t)^{\alpha}
$$

Where $x$ is real and the integral is treated as a Canchy principal value, that is,

$$
\begin{aligned}
& \frac{1}{\Gamma(1+\alpha)} f_{R} \frac{f(t)}{(t-x)^{\alpha}}(d t)^{\alpha} \\
& =\lim _{\varepsilon \rightarrow 0}\left[\frac{1}{\Gamma(1+\alpha)} \int_{-\infty}^{x-\varepsilon} \frac{f(t)}{(t-x)^{\alpha}}(d t)^{\alpha}+\right. \\
& \left.\frac{1}{\Gamma(1+\alpha)} \int_{x+\varepsilon}^{\infty} \frac{f(t)}{(t-x)^{\alpha}}(d t)^{\alpha}\right]
\end{aligned}
$$

To obtain the inverse local fractional Hilbert transform, write again Eq. (4) as

$$
\begin{aligned}
& \hat{f}_{H}^{\alpha}(x)=\frac{1}{\Gamma(1+\alpha)} \int_{-\infty}^{\infty} \frac{f(t)}{(t-x)^{\alpha}}(d t)^{\alpha} \\
& =\frac{1}{\Gamma(1+\alpha)} \int_{-\infty}^{\infty} f(t) g(x-t)(d t)^{\alpha} \\
& =f(x) * g(x),
\end{aligned}
$$

\section{THE EXPERIMENT AND DATA ANALYSIS}

Samples are chose for the questionnaire test. The comparison of local fractional algorithm and AES can be seen from Fig. (1). The result shows that in the same comparison time, the local fractional algorithm achieves better performance than AES in calculation capability.

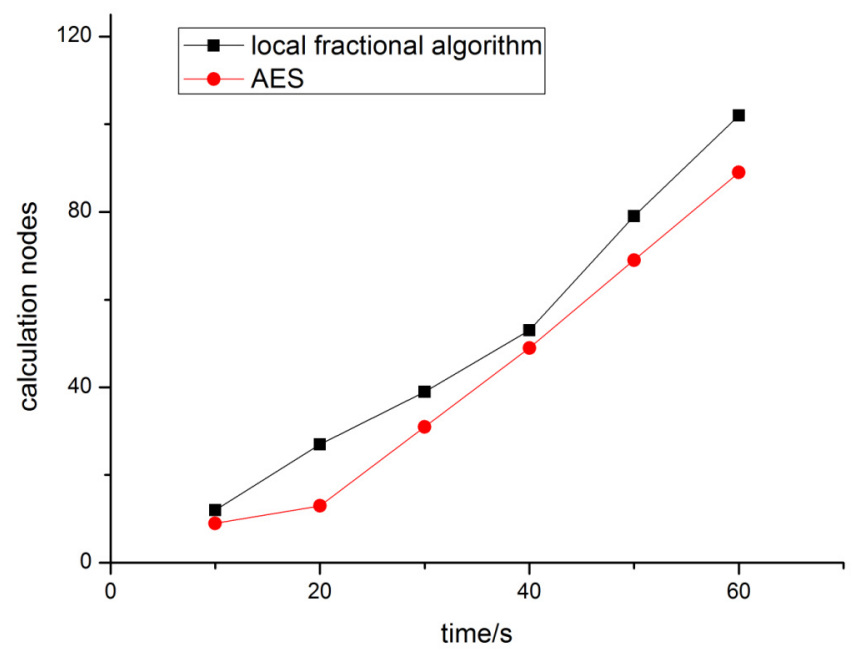

Fig. (1). The volatility of the sample.

The comparison of local fractional algorithm and DSS can be seen from Fig. (2). The result shows that in the same comparison time, the local fractional algorithm achieves better performance than DSS in calculation capability.

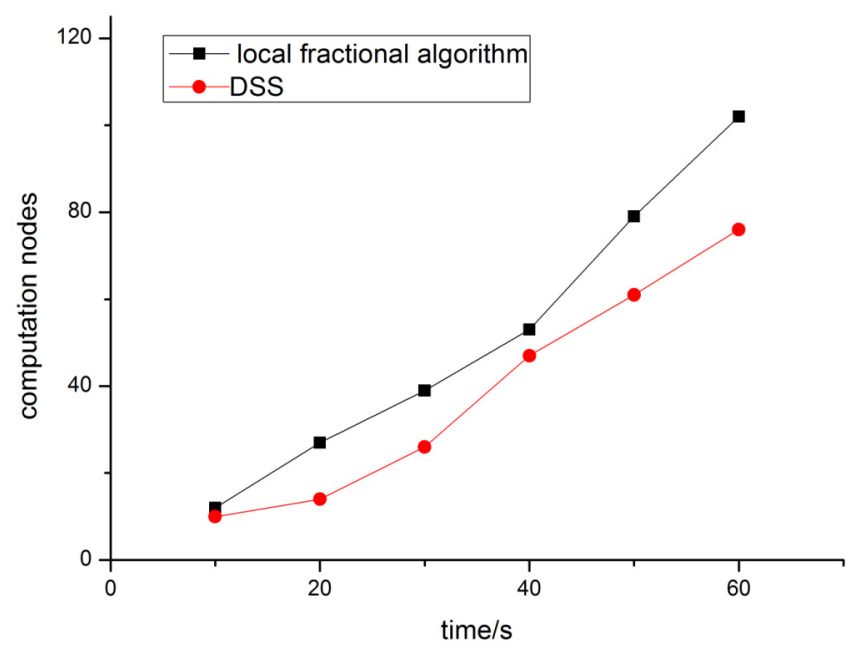

Fig. (2). The comparison of local fractional algorithm and DSS. 


\section{CONCLUSION}

This paper takes the public value as a basic framework to build a system and it combines the execution process of ecological construction policies with the performance evaluation of the ecological effects. Then it extracts index factors from some aspects such as the "fairness" of the policy process, respect for the subject of "co-production", the management "efficiency" of the government departments, the "sustainability" of ecological effects. and so on. The analytic hierarchy process and local fractional algorithm is used to calculate the weight of each index factor. Different ecological construction polices have different performance evaluation values with implementation effects based on the public value. Returning farmland to forest and natural forest protection policies have good effects with scores of 0.9297 and 0.8531 respectively: Three-North Shelter-belt policy has a general effect with a score of 0.5755 : Grassland grazing prohibition policy has a poor effect with a score of 0.3661 .

\section{CONFLICT OF INTEREST}

The author confirms that this article content has no conflict of interest.

\section{ACKNOWLEDGEMENTS}

This work is supported by the Science Project of Science and Technology Department of Gansu Province (No. 1305ZCRA170)

\section{REFERENCES}

[1] S. Smulders, "Economic growth and environmental quality. In: $\mathrm{H}$ Folmer, L. Gabel, Eds., "Principles of Environmental Economics. Cheltenham: Edward Elgar," 2007, pp. 688-699.

[2] S. P. Osrorne, "The New Public Governance?", Emerging Perspectives on the Theory and Practise of Public Govemance. London: Rout ledge, 2010.

[3] Y.Z. Luo, "Network System Integration and Management". Beijing: People's Posts and Telecommunications Publishing House, 2005, pp. 128-132.

[4] S. Gattoufi, M. Oral, and A. Reisman, "Data envelopment analysis literature: a bibliography update (1951-2001)," Socio-Economic Planning Sciences, no. 38, pp. 159-229, 2004.

[5] J. A. T. Machado, M. F. Silva, R. S. Barbosa, I. S. Jesus, C. M. Reis, M. G. Marcos, and A. F. Galhano, "Some applications of fractional calculus in engineering", Mathematical Problems in Engineering, Hindawi, vol. 2, 2010.

[6] S.G. Samko, A.A. Kilbas, and O.I. Marichev, "Fractional integrals and derivatives: theory and applications," Gordon and Breach, pp. 164-170, 1993.

[7] K.M. Kolwankar, and A.D. Gangal, "Local fractional fokker-planck equation," Physics Review Letters, no. 80, pp. 214-217, 1998.

[8] A. Babakhani, and V. Daftardar-Gejji, "On calculus of local fractional derivatives," Journal Mathematical Analysis and Application, no. 270, pp. 66-79, 2002 